University of Nebraska - Lincoln

DigitalCommons@University of Nebraska - Lincoln

8-1-2006

\title{
Total dissociative electron attachment cross sections for molecular constituents of DNA
}

\author{
Kayvan Aflatooni \\ University of Nebraska-Lincoln, kaflatoo@fhsu.edu
}

A.M. Scheer

University of Nebraska - Lincoln

Paul Burrow

pburrow1@unl.edu

Follow this and additional works at: https://digitalcommons.unl.edu/physicsburrow

Part of the Physics Commons

Aflatooni, Kayvan; Scheer, A.M.; and Burrow, Paul, "Total dissociative electron attachment cross sections for molecular constituents of DNA" (2006). Paul Burrow Publications. 32.

https://digitalcommons.unl.edu/physicsburrow/32

This Article is brought to you for free and open access by the Research Papers in Physics and Astronomy at DigitalCommons@University of Nebraska - Lincoln. It has been accepted for inclusion in Paul Burrow Publications by an authorized administrator of DigitalCommons@University of Nebraska - Lincoln. 


\title{
Total dissociative electron attachment cross sections for molecular constituents of DNA
}

\author{
K. Aflatooni, ${ }^{\text {a) }}$ A. M. Scheer, and P. D. Burrow ${ }^{\text {b) }}$ \\ Department of Physics and Astronomy, University of Nebraska-Lincoln, Lincoln, Nebraska 68588-0111
}

(Received 26 May 2006; accepted 22 June 2006; published online 1 August 2006)

\begin{abstract}
Total cross sections for the dissociative electron attachment process are presented for the DNA bases thymine, cytosine, and adenine and for three compounds used as surrogates for the ribose and phosphate groups, tetrahydrofuran, 3-hydroxytetrahydrofuran, and trimethylphosphate, respectively. Cross section magnitudes are obtained by observation of positive ion production and normalization to ionization cross sections calculated elsewhere using the binary-encounter-Bethe method. The average cross section of the three bases is 3-10 times smaller than the effective cross section per nucleotide reported for single strand breaks in surface-bound supercoiled DNA. Consequently, damage to the bases alone does not appear to account for the major portion of the strand breaks. The presence of an $\mathrm{OH}$ group on the ribose surrogate considerably enhances its cross section. Model compounds in which protonation or $\mathrm{OH}$ groups are used to terminate bonds may therefore display larger cross sections than in DNA itself. () 2006 American Institute of Physics.
\end{abstract}

[DOI: $10.1063 / 1.2229209$ ]

\section{INTRODUCTION}

Low energy electron attachment to DNA is known to cause single and double strand breaks by means of the dissociative electron attachment (DEA) process. ${ }^{1,2}$ Since this discovery, research has focused on the specific mechanisms causing the damage. Examination of bond breaking initiated by electron impact on the gas phase constituents of DNA has greatly contributed to understanding these processes. Although considerable progress has been made, the structures appearing in the DEA cross sections have not been comprehensively identified. Furthermore, total cross sections have not been available for comparison with the effective strand break cross sections for electrons impinging on supercoiled DNA. ${ }^{3,4}$ Thus the relevance of particular DEA reactions to DNA strand breaks cannot be easily gauged.

In this paper we report DEA cross sections as a function of electron energy for total negative ion production below the onset of positive ionization in the DNA bases thymine, cytosine, and adenine. Cross sections are also provided for trimethylphosphate (TMP), used as an analog to the phosphate group in DNA, and two molecules commonly used to model the deoxyribose ring, namely, tetrahydrofuran (THF) and 3-hydroxytetrahydrofuran (3-hTHF). In contrast to earlier estimates of the cross sections for the DNA bases in the gas phase, the values reported here are substantially smaller. We indicate two mechanisms giving rise to peaks in the DEA cross sections of the bases below $4 \mathrm{eV}$ and argue that only one of these will be relevant in the condensed phase. Finally, our results on the ribose surrogates show that the DEA cross sections are greatly enhanced by the presence of $\mathrm{OH}$ groups.

\footnotetext{
${ }^{a)}$ Permanent address: Department of Physics, Fort Hays State University, Hays, KS 67601.

b) Author to whom correspondence should be addressed. Electronic mail: pburrow1@unl.edu
}

Thus, cross sections for 2-deoxy-D-ribose itself, which contains three such groups, will not be representative of the ribose group in DNA. Furthermore, compounds in which the negatively charged phosphate group is protonated or in which $\mathrm{OH}$ groups are used to terminate bonds may also show enhanced DEA cross sections with respect to that of DNA.

\section{EXPERIMENT}

Our apparatus consists of a modified electron transmission spectrometer (ETS) used previously to determine the vertical attachment energies (VAEs) of the DNA bases. ${ }^{5}$ As in the transmission mode, a magnetically collimated trochoidal monochromator ${ }^{6}$ is used to supply an energy selected electron beam. In the present application, a beam of 50-80 nA was employed with a resolution of $100-150 \mathrm{meV}$. The energy scale was calibrated by reference to the $2.25 \mathrm{eV}$ DEA peak in $\mathrm{O}^{-}$observed by the addition of $\mathrm{N}_{2} \mathrm{O}$ to the cell. The spectrometer has been modified by the addition of guard electrodes on both ends of the currentcollecting electrode to permit measurement of small currents with a vibrating reed electrometer. An oven containing the sample powder is attached directly to the collision cell. The sample oven and collision cell temperatures are independently controlled, with the cell maintained about $10^{\circ} \mathrm{C}$ warmer. Approximate oven temperatures employed were thymine $\left(155^{\circ} \mathrm{C}\right)$, cytosine $\left(200^{\circ} \mathrm{C}\right)$, and adenine $\left(160^{\circ} \mathrm{C}\right)$. At room temperature, TMP, THF, and 3-hTHF have sufficient vapor pressures to be introduced into the collision cell by means of an external leak valve, and these data were acquired at $\approx 60{ }^{\circ} \mathrm{C}$.

By collection of total ion current arriving at the walls of a static collision cell, the ratio of negative ion current measured at low electron impact energies to the positive ion current produced at the maximum of the ionization cross section could be determined. Absolute DEA cross sections are ob- 


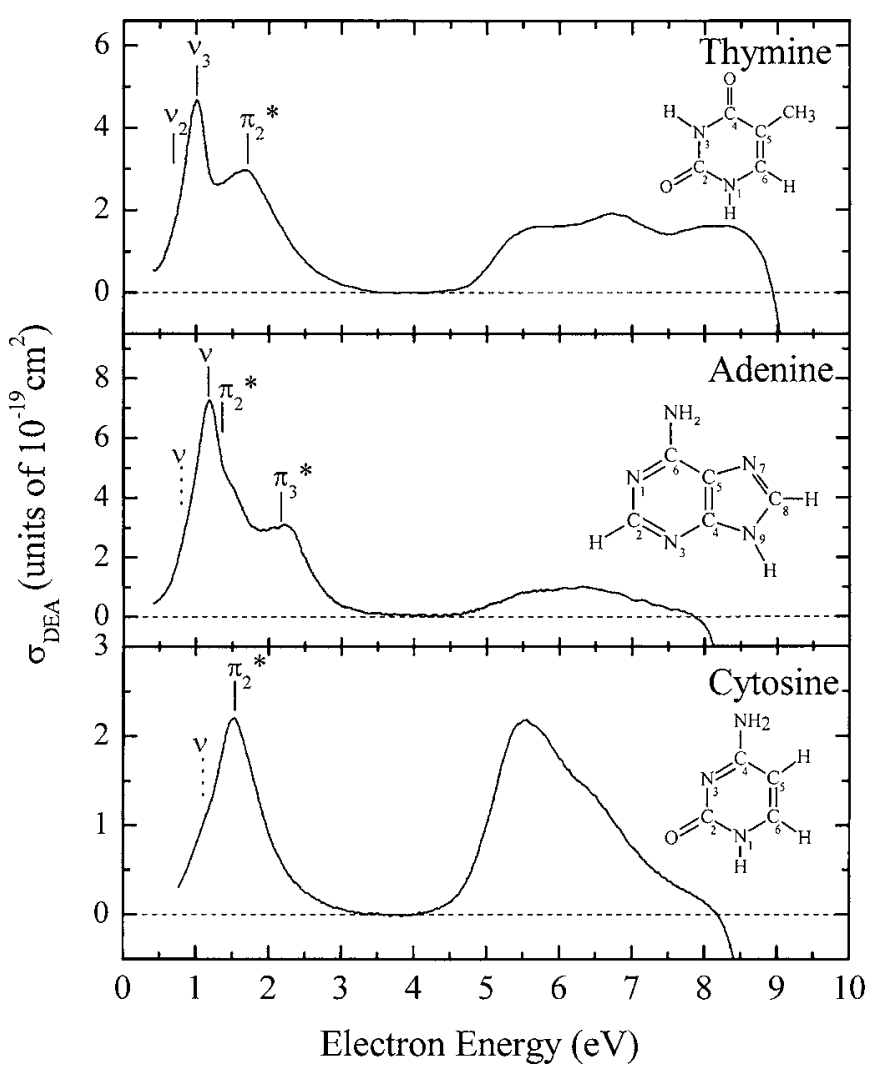

FIG. 1. Total dissociative electron attachment cross sections as a function of electron energy for thymine, adenine, and cytosine. The solid vertical lines indicate the energies of $\pi^{*}$ shape resonances determined by electron transmission spectroscopy. Vertical lines labeled "v" indicate vibrational Feshbach resonances. The dotted lines show positions of additional narrow features located by others.

tained by normalization to positive ionization cross sections calculated elsewhere using the binary-encounter-Bethe (BEB) approach. ${ }^{7,8}$ Calculations made by the Deutsch-Märk ${ }^{9}$ (DM) semiempirical method give quite similar results.

The potentials on the entrance and exit electrodes of the collision cell were adjusted to keep the cell as electric fieldfree as possible. However, because of the short length of the collision cell, losses of ions with differing kinetic energies at the ends are the primary source of error. The apparatus was tested in $\mathrm{N}_{2} \mathrm{O}$ by measuring the ratio of anion current at the well studied $2.25 \mathrm{eV}$ DEA peak to the cation current at the maximum in the positive ionization cross section $(115 \mathrm{eV})$. The ratio of the two was within $10 \%$ of the ratio of the known cross sections for the DEA (Ref. 10) and ionization ${ }^{11}$ processes. Nevertheless, because of the sensitivity of the currents to the entrance and exit voltage, we estimate that errors in the ratio measurements for anion currents below $4 \mathrm{eV}$ in the DNA bases could be as high as $\pm 50 \%$. In the $4-8 \mathrm{eV}$ range, the anion currents appear to be less sensitive to end effects, and the error is estimated to be less than $\pm 25 \%$.

\section{RESULTS}

\section{A. DNA bases}

In Fig. 1 we present the total DEA cross sections of the DNA bases thymine, adenine, and cytosine as a function of electron energy. Before discussing their magnitudes, we re- capitulate briefly the mechanisms producing the low energy structures. Below $4 \mathrm{eV}$, studies carried out elsewhere using mass analysis show that the anion yields from thymine, ${ }^{12-14}$ adenine, ${ }^{14,15}$ and cytosine ${ }^{13,14}$ consist only of the parent molecular anion minus a $\mathrm{H}$ atom, represented here by $(M$ $-\mathrm{H})^{-}$. Furthermore, in thymine and the related RNA base uracil, ${ }^{16}$ which have been studied most extensively, the yield is site selective. Using deuterium substitution, AbdoulCarime et al. ${ }^{14}$ found that $\mathrm{H}$ loss occurred only from the nitrogen positions. With methyl group substitution at $\mathrm{N}_{1}$ or $\mathrm{N}_{3}$ (where the subscripts correspond to the site numbering in Fig. 1), Ptasinska et al. ${ }^{17}$ found that the energy dependence of the DEA yields was strikingly different. As discussed more completely elsewhere, ${ }^{18} \mathrm{H}$ atoms released from the $\mathrm{N}_{3}$ site in thymine and uracil are produced by coupling between the temporary anion states associated with the $\pi^{*}$ and $\sigma^{*}$ valence orbitals owing to out of plane vibrational motion. Such a mechanism is well known in planar chloroalkenes and phenylchlorides ${ }^{19}$ and produces peak anion yields quite near the energies of the $\pi^{*}$ temporary anion states. Vertical lines labeled $\pi^{*}$ in Fig. 1 indicate the energies of temporary anion states associated with the normally unoccupied $\pi^{*}$ orbitals of the bases as determined by ETS. ${ }^{5}$

In contrast, $\mathrm{H}$ atoms ejected from the $\mathrm{N}_{1}$ site of thymine and uracil arise from sharp vibrational Feshbach resonances $^{20,21}$ (VFRs) created by mixing of the dipole bound negative ion states (DBSs) of these compounds with the temporary negative ion states associated with the lowest normally unoccupied valence $\sigma^{*}$ molecular orbital. VFRs corresponding to three distinct vibrational modes of the dipole bound state have been identified in high energy resolution data. ${ }^{18}$ Vertical lines labeled $v$ in Fig. 1 point out these sharp features. The lowest lying VFRs in each compound are not seen in our low energy resolution data. The dotted lines are shown at the energies given in Ref. 13 for thymine and cytosine and Ref. 15 for adenine.

Above $4 \mathrm{eV}$, production of anion fragments takes place through the formation of core-excited (CE) negative ion states. As shown by Ptasinska et al., ${ }^{2,23}$ the yield of $\mathrm{H}^{-}$from thymine and uracil over the $5-12 \mathrm{eV}$ range is also characterized by site selectivity, as determined in experiments using deuterium and methyl group substitution. Numerous other ion fragments have also been observed in this energy range. ${ }^{13}$ Detailed orbital assignments for the core-excited resonances have not yet been determined.

In each panel of Fig. 1, the apparent drop in anion current at high energies reflects the onset of positive ionization. Table I summarizes the BEB ionization cross sections at their maxima used for normalization, ${ }^{7,8}$ the energies of the anion peaks, the cation/anion current ratios, and the peak DEA cross sections determined from these. We also list the $\pi^{*}$ energies observed by ETS (Ref. 5) and give an indication of the mechanism by which DEA takes place.

\section{B. THF, 3-hTHF, and TMP}

Figure 2 shows the DEA cross sections for two compounds, THF and 3-hTHF, frequently used to model the deoxyribose ring of DNA and that for TMP, a surrogate for 
TABLE I. Peak ionization cross sections computed by the binary-encounter-Bethe (BEB) procedure, cation/ anion ratios for selected features, and the normalized total dissociative electron attachment (DEA) cross sections.

\begin{tabular}{|c|c|c|c|c|c|c|}
\hline Compound & $\begin{array}{c}\text { BEB peak } \\
\text { ionization } \\
\text { cross } \\
\text { section } \\
\left(10^{-16} \mathrm{~cm}^{2}\right)\end{array}$ & $\begin{array}{c}\text { Cation/anion } \\
\text { ratio }\end{array}$ & $\begin{array}{c}\text { Electron } \\
\text { energy } \\
(\mathrm{eV})\end{array}$ & $\begin{array}{c}\text { DEA } \\
\text { cross } \\
\text { section } \\
\left(10^{-19} \mathrm{~cm}^{2}\right)\end{array}$ & $\begin{array}{c}\pi^{*} \\
\text { energies } \\
\text { from } \\
\text { ETS }^{\mathrm{b}} \\
(\mathrm{eV})\end{array}$ & $\begin{array}{c}\text { DEA } \\
\text { mechanism }\end{array}$ \\
\hline \multirow[t]{4}{*}{ Thymine } & 16.18 & & & & & \\
\hline & & 3500 & 1.01 & 4.7 & & $\mathrm{DBS} / \sigma^{*}$ \\
\hline & & 5400 & 1.7 & 3.0 & 1.71 & $\pi^{*} / \sigma^{*}$ \\
\hline & & 6500 & 6.63 & 2.5 & & $\mathrm{CE}^{\mathrm{d}}$ \\
\hline \multirow[t]{3}{*}{ Cytosine } & 14.58 & & & & & \\
\hline & & 6600 & 1.54 & 2.2 & 1.53 & $\pi^{*} / \sigma^{*}$ \\
\hline & & 6600 & 5.48 & 2.2 & & $\mathrm{CE}$ \\
\hline \multirow[t]{4}{*}{ Adenine } & 18.16 & & & & & \\
\hline & & 2500 & 1.18 & 7.1 & & $\mathrm{DBS} / \sigma^{*}$ \\
\hline & & 6000 & 2.17 & 2.9 & 2.17 & $\pi^{*} / \sigma^{*}$ \\
\hline & & 20000 & 6.28 & 0.88 & & $\mathrm{CE}$ \\
\hline \multirow[t]{2}{*}{ THF } & 12.9 & & & & & \\
\hline & & 80000 & 6.2 & 0.16 & & $\mathrm{CE}$ \\
\hline \multirow[t]{2}{*}{ 3-hTHF } & 6.18 & & & & & \\
\hline & & 2900 & 6.18 & 4.9 & & $\mathrm{CE}$ \\
\hline \multirow[t]{2}{*}{ TMP } & $9.52^{\mathrm{e}}$ & & & & & \\
\hline & & 53000 & 7.43 & 0.18 & & $\mathrm{CE}$ \\
\hline
\end{tabular}

the phosphate group. The range of energies over which anion fragments could be detected suggests that only core-excited temporary negative ion states are involved. The lower part of Table I summarizes the data for these compounds. A BEB ionization cross section for TMP was not available. The calculated value for $\mathrm{H}_{3} \mathrm{PO}_{4}$ was used in Table I. Consequently, the DEA cross section for TMP is likely to be slightly underestimated.

\section{DISCUSSION}

\section{A. DNA bases}

\section{Magnitudes}

DEA cross sections for the three bases range from $(1-7) \times 10^{-19} \mathrm{~cm}^{2}$ at the various peaks shown in Fig. 1, with the contributions from the core-excited region roughly comparable in magnitude to those from the shape and VF resonances below $4 \mathrm{eV}$ in cytosine and thymine, but smaller in adenine. The onset of positive ionization obliterates structure lying above $\sim 8 \mathrm{eV}$, where data using mass analysis in thymine show additional peaks near 8.6 and $10 \mathrm{eV} .{ }^{13}$ A number of estimates of the thymine cross section at $1 \mathrm{eV}$ have been made, ${ }^{12-14}$ all giving $\sim 10^{-15} \mathrm{~cm}^{2}$. Similarly, the cytosine cross section at $1.54 \mathrm{eV}$ has been reported ${ }^{13}$ as 2.3 $\times 10^{-16} \mathrm{~cm}^{2}$. Cytosine and adenine are stated ${ }^{14}$ to be of the same magnitude as thymine, namely, $\sim 10^{-15} \mathrm{~cm}^{2}$. More recently, the cross section for $\mathrm{H}^{-}$production from thymine at
$5.5 \mathrm{eV}$ was reported ${ }^{22}$ as $1.2 \times 10^{-17} \mathrm{~cm}^{2}$, substantially larger than the cross sections obtained from our total anion current measurements at this energy. Because cross section calibration in the mass analyzed work appears to be carried out using relative ion gauge readings of the static pressure in the vacuum chamber rather than in the molecular beam, condensation of the target gas on the chamber walls may substantially reduce its density relative to that of the calibrant gas, which is usually $\mathrm{SF}_{6}$ or $\mathrm{CCl}_{4}$. As earlier authors have recognized, these estimates should thus be taken as upper bounds.

\section{VFRs}

The largest single feature in the thymine cross section, labeled $v_{3}$ in Fig. 1, and a small, very narrow peak appearing in the high resolution data of others ${ }^{12-14,24}$ indicated here by $\mathrm{v}_{2}$ have been interpreted ${ }^{20,21}$ as VFRs associated with the excitation of the second and third $\mathrm{N}_{1}-\mathrm{H}$ stretching vibrations of the dipole bound anion state, followed by tunneling of $\mathrm{H}$ through the barrier created by the avoided crossing of this state with the lowest valence $\sigma_{1}^{*}$ anion state. Molecular orbital calculations presented in Ref. 18 illustrate the spatial overlap between the $\sigma_{1}^{*}$ valence orbital and the wave function of the dipole bound state.

In Fig. 3(a) we show the lowest $\sigma_{1}^{*}$ valence molecular orbital of adenine and note that it is localized primarily on the $\mathrm{N}_{9}-\mathrm{H}$ bond. The arrow shows the direction of the elec- 


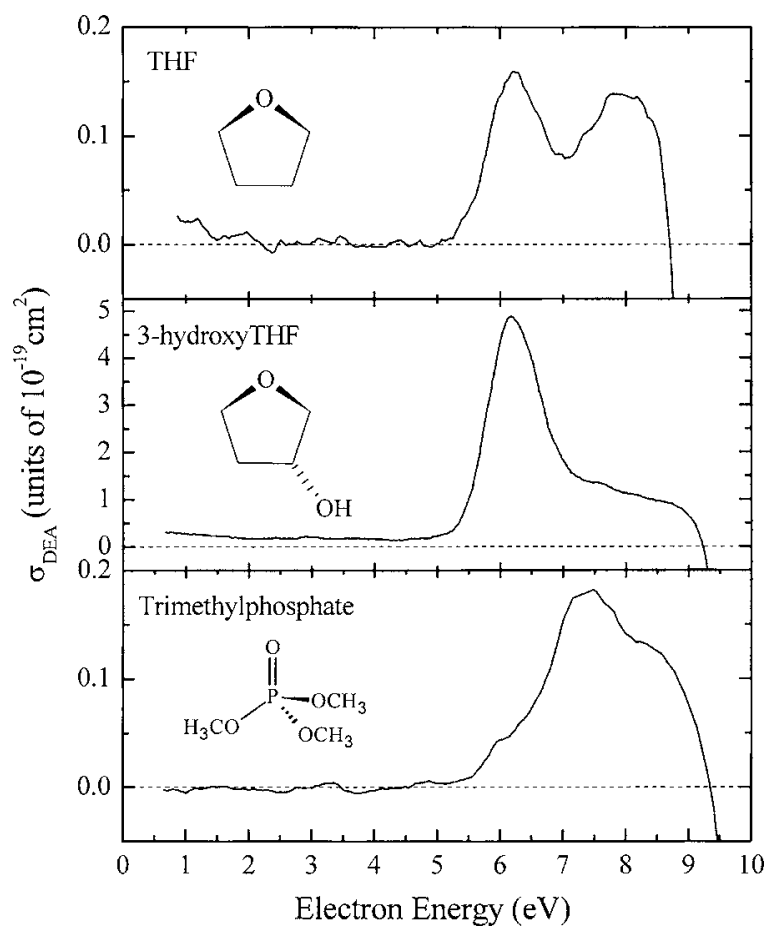

FIG. 2. Total dissociative electron attachment cross sections of tetrahydrofuran (THF), 3-hydroxytetrahydrofuran (3-hTHF), and trimethylphosphate.

tric dipole moment, of magnitude $2.3 \mathrm{D},{ }^{25}$ and indicates that the electron in the dipole bound anion state lies off the $\mathrm{C}_{8}-\mathrm{H}$ end of the molecule. The wave function overlap with $\sigma_{1}^{*}$ is therefore not as substantial as in thymine; however, the features labeled $\mathrm{v}$ in the adenine DEA cross section are likely to correspond to VFRs associated with the excitation of the $\mathrm{N}_{9}-\mathrm{H}$ stretching vibration of the dipole bound anion.

High resolution data in cytosine ${ }^{13}$ show one small feature at $1.1 \mathrm{eV}$ that we attribute to a VFR. There are two tautomers of cytosine likely to be present at the temperatures we employ. ${ }^{26}$ The keto form of the tautomer has the lowest lying $\sigma_{1}^{*}$ valence orbital, shown in Fig. 3(b). The direction of the supercritical moment, 6.6 D (Ref. 25), shows that a dipole bound electron would lie off the $\mathrm{C}_{5}-\mathrm{H}$ end of the molecule. The weakness of the $1.1 \mathrm{eV}$ feature may reflect the relatively poor overlap of the dipole bound orbital with $\sigma_{1}^{*}$ at the $\mathrm{N}_{1}-\mathrm{H}$ site. Further studies with methyl substituted cytosine would illuminate the stretching vibration responsible for the VFR.

Attempts to study the remaining DNA base, guanine, were unsuccessful in our apparatus, with considerable indication that the compound was partially decomposed. In the original ETS study of this compound, ${ }^{5}$ we noted that the results did not match the molecular orbital calculations as well as in the other bases and suggested that other tautomers might be present. It would appear that decomposition products may also be present, although the ETS signal is less sensitive to them than the DEA measurements. The only published work on guanine we are aware of is that of AbdoulCarime et al. ${ }^{14}$ who reported a peak in production of $(\mathrm{G}-\mathrm{H})^{-}$ near $1.7 \mathrm{eV}$. They note, however, that this signal was an order of magnitude smaller than that of $\mathrm{NCO}^{-}$. The latter could arise from products of thermal decomposition. (a)

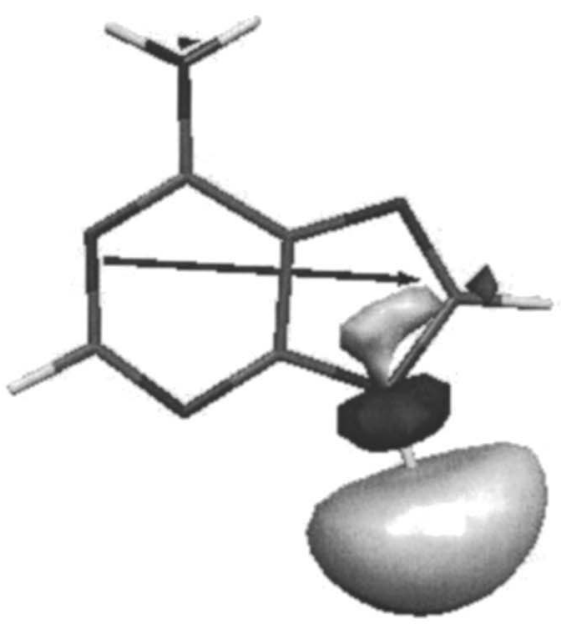

(b)

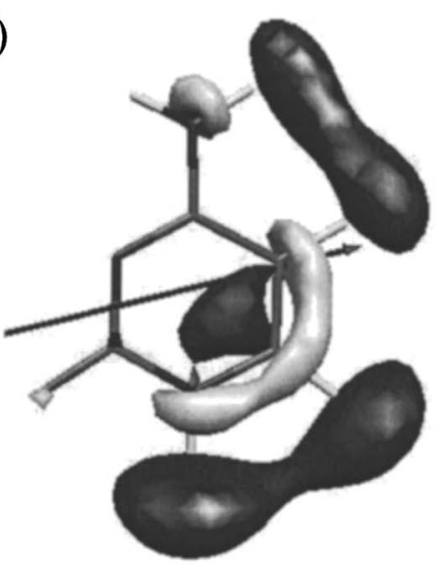

FIG. 3. Hartree-Fock calculation of the lowest valence $\sigma_{1}^{*}$ orbitals of (a) adenine and (b) cytosine (keto tautomer), using a 6-31G(d) basis set. The arrows indicate the directions of the electron dipole moments.

\section{B. Ribose and phosphate surrogates}

The DEA cross sections of THF and TMP are an order of magnitude smaller than those of the DNA bases and lie at the detection limits of our apparatus in its present form. The presence of the $\mathrm{OH}$ group in 3-hTHF causes an enhancement of approximately 30 in the total DEA cross section over that of THF at $6.2 \mathrm{eV}$. Consequently, we suggest that a compound such as deoxyribose (2-deoxy-D-ribose) ${ }^{27}$ which contains three $\mathrm{OH}$ groups, will have an even larger DEA cross section and is not a suitable model for the response of the sugar ring in DNA, which does not possess these groups. The large cross sections reported in Ref. 27 may also be a result of the cross section calibration procedure, and the possibility of thermal degradation cannot be ignored. We further note that the presence of $\mathrm{OH}$ groups on the phosphate moiety, occurring by protonation of the $\mathrm{O}^{-}$atom, may also enhance its DEA cross section relative to that in "normal" DNA which possesses a heavy counter ion near this site. Such $\mathrm{OH}$ bearing groups appear in self-assembled films of DNA. ${ }^{28}$

\section{DNA strand breaks}

A comparison of the DEA results measured here with the cross sections for strand breaks in DNA is instructive but 
must be accompanied with a number of caveats. A recent paper from Panajotovic et $\mathrm{al}^{4}{ }^{4}$ has revised the magnitude of the single strand break (SSB) cross sections presented in Refs. 1 and 3 and has calibrated the data in the shape resonance region ${ }^{2}$ at $0.8 \mathrm{eV}$ against that proceeding through core-excited resonances at $10 \mathrm{eV}$. Expressed per nucleotide, the SSB cross section at $10 \mathrm{eV}$ is $1.7 \times 10^{-18} \mathrm{~cm}^{2} \pm 50 \%{ }^{4}$

Because of the limited energy range of our measurements, the most direct comparison with these data can be made at $5.5 \mathrm{eV}$. At this energy the data of Boudaiffa et al. ${ }^{1,3}$ show a small peak in the production of SSBs in supercoiled DNA which is four times smaller than that at $10 \mathrm{eV}$. Combined with the new value, this yields a cross section per nucleotide of $4.3 \times 10^{-19} \mathrm{~cm}^{2}$. For comparison, the average DEA cross section of the three bases measured here at $5.5 \mathrm{eV}$ is $1.6 \times 10^{-19} \mathrm{~cm}^{2} \pm 25 \%$, a factor of 2.7 smaller. It should be noted, however, that in the gas phase, an unknown portion of the thymine signal at this energy arises from $\mathrm{H}^{-}$ production from the $\mathrm{N}_{1}$ position. A similar contribution is likely from cytosine and adenine from the $\mathrm{N}_{1}$ and $\mathrm{N}_{9}$ sites, respectively. These $\mathrm{H}$ atoms are not available in DNA since these sites are tied to ribose groups. Consequently, the difference with the SSB cross section may be even larger.

A detailed comparison of the DEA cross sections with those for SSBs below $4 \mathrm{eV}$ is not so straightforward, except for the general order of magnitude. The contributions from VFRs, the features indicated as $\mathrm{v}$ in Fig. 1, must not be included since these arise from dipole bound anion states that are not likely to exist in the condensed phase. In addition, these features appear to be associated with $\mathrm{H}$ atoms on the $\mathrm{N}$ sites which are tied to the ribose group in DNA. Furthermore, identification of the resonances responsible for the peak SSB cross sections with those in Fig. 1 is not certain. An attempt ${ }^{2}$ to fit the SSB cross sections with model resonances located at the known shape resonance energies required the latter to be shifted to higher energies by $0.41 \mathrm{eV}$. This was attributed to incomplete counterion screening of the charged phosphate groups. If we take the SSB cross section ${ }^{4}$ near $2.2 \mathrm{eV},(2.8 \pm 0.5) \times 10^{-18} \mathrm{~cm}^{2}$, to correspond to the average of our DNA base DEA cross sections in the $1.5-2 \mathrm{eV}$ range, $\approx 3 \times 10^{-19} \mathrm{~cm}^{2} \pm 50 \%$, we see that the latter are a factor of 10 smaller. In this energy range, the DEA cross sections report only one decay channel, namely, the ejection of one $\mathrm{H}$ atom from the bases by the mechanism discussed earlier.

In the energy ranges corresponding to both shape and core-excited temporary anion states, it appears that the DEA cross sections reported here signal the damage occurring to the bases themselves rather than effects arising from the transport of the electron and bond breaking at a remote site. Thus they account for only a portion of the SSB cross sections.

\section{CONCLUSIONS}

Total DEA cross sections for the three DNA bases have roughly comparable magnitudes in the energy ranges in which shape and core-excited temporary anion states are formed. However, they are 3-10 times smaller than the cross sections for SSBs reported elsewhere, suggesting that damage to the bases alone does not account for most SSBs. The DEA cross sections for molecular surrogates of the phosphate and ribose groups are even smaller in magnitude. The presence of an $\mathrm{OH}$ group on the latter is observed to substantially increase the DEA cross section implying that other models containing these groups will not accurately emulate the cross section in DNA.

\section{ACKNOWLEDGMENT}

The authors are indebted to Gordon Gallup for many useful discussions.

${ }^{1}$ B. Boudaiffa, P. Cloutier, D. Hunting, M. A. Huels, and L. Sanche, Science 287, 1658 (2000).

${ }^{2}$ F. Martin, P. D. Burrow, Z. Cai, P. Cloutier, D. Hunting, and L. Sanche, Phys. Rev. Lett. 93, 068101 (2004).

${ }^{3}$ B. Boudaiffa, P. Cloutier, D. Hunting, M. A. Huels, and L. Sanche, Radiat. Res. 157, 227 (2002).

${ }^{4}$ R. Panajotovic, F. Martin, P. Cloutier, D. Hunting, and L. Sanche, Radiat. Res. 165, 452 (2006)

${ }^{5}$ K. Aflatooni, G. A. Gallup, and P. D. Burrow, J. Phys. Chem. A 102, 6205 (1998).

${ }^{6}$ A. Stamatovic and G. J. Schulz, Rev. Sci. Instrum. 41, 423 (1970).

${ }^{7}$ Ph. Bernhardt and H. G. Paretzke, Int. J. Mass. Spectrom. 223, 599 (2003).

${ }^{8}$ P. Mozejko and L. Sanche, Radiat. Phys. Chem. 73, 77 (2005).

${ }^{9}$ H. Deutsch, K. Becker, S. Matt, and T. D. Märk, Int. J. Mass. Spectrom. 197, 37 (2000).

${ }^{10}$ D. Rapp and D. D. Briglia, J. Chem. Phys. 43, 1480 (1965).

${ }^{11}$ D. Rapp and P. Englander-Golden, J. Chem. Phys. 43, 1464 (1965).

${ }^{12}$ R. Abouaf, J. Pommier, and H. Dunet, Int. J. Mass. Spectrom. 226, 397 (2003).

${ }^{13}$ S. Denifl, S. Ptasinska, M. Cingel, S. Matejcik, P. Scheier, and T. D. Märk, Chem. Phys. Lett. 377, 74 (2003); S. Denifl, S. Ptasinska, M. Probst, J. Hrusak, P. Scheier, and T. D. Märk, J. Phys. Chem. A 108, 6562 (2004).

${ }^{14}$ H. Abdoul-Carime, S. Gohlke, and E. Illenberger, Phys. Rev. Lett. 92, 168103 (2004).

${ }^{15}$ S. Gohlke, H. Abdoul-Carime, and E. Illenberger, Chem. Phys. Lett. 380, 595 (2003).

${ }^{16}$ G. Hanel, B. Gstir, S. Dennifl, P. Scheier, M. Probst, B. Farizon, M. Farizon, E. Illenberger, and T. D. Märk, Phys. Rev. Lett. 90, 188104 (2003); S. Denifl, S. Ptasinska, G. Hanel, B. Gstir, M. Probst, P. Scheier, and T. D. Märk, J. Chem. Phys. 120, 6557 (2004).

${ }^{17}$ S. Ptasinska, S. Denifl, P. Scheier, E. Illenberger, and T. D. Märk, Angew. Chem., Int. Ed. 44, 6941 (2005).

${ }^{18}$ P. D. Burrow, G. A. Gallup, A. M. Scheer, S. Denifl, S. Ptasinska, T. Märk, and P. Scheier, J. Chem. Phys. 124, 124310 (2006).

${ }^{19}$ T. Skalicky, C. Chollet, N. Pasquier, and M. Allan, Phys. Chem. Chem. Phys. 4, 3583 (2002).

${ }^{20}$ A. M. Scheer, K. Aflatooni, G. A. Gallup, and P. D. Burrow, Phys. Rev. Lett. 92, 068102 (2004).

${ }^{21}$ A. M. Scheer, C. Silvernail, J. A. Belot, K. Aflatooni, G. Gallup, and P. D. Burrow, Chem. Phys. Lett. 411, 46 (2005).

${ }^{22}$ S. Ptasinska, S. Denifl, V. Grill, T. D. Märk, P. Scheier, S. Gohlke, M. A. Huels, and E. Illenberger, Angew. Chem., Int. Ed. 44, 1647 (2005).

${ }^{23}$ S. Ptasinska, S. Denifl, V. Grill, T. D. Märk, E. Illenberger, and P. Scheier, Phys. Rev. Lett. 95, 093201 (2005).

${ }^{24}$ R. Abouaf and H. Dunet, Eur. Phys. J. D 35, 405 (2005).

${ }^{25}$ J. Li, J. Xing, C. J. Cramer, and D. G. Truhlar, J. Chem. Phys. 111, 885 (1999).

${ }^{26}$ D. Estrin, L. Pagliere, and G. Corongiu, J. Phys. Chem. 98, 5653 (1994).

${ }^{27}$ S. Ptasinska, S. Denifl, P. Scheier, and T. D. Märk, J. Chem. Phys. 120, 8505 (2004).

${ }^{28}$ X. Pan and L. Sanche, Phys. Rev. Lett. 94, 198104 (2005). 